\title{
A fluida zona linguística das causalidades: áreas de contraste e de sobreposição ${ }^{1}$
}

\author{
The fluid linguistic zone of causalities: areas of contrast and overlap
}

\section{Andre Vinicius Lopes Coneglianos}

Universidade Presbiteriana Mackenzie - UPM - São Paulo - São Paulo - Brasil

\begin{abstract}
Resumo:Este artigo propõe-se a uma investigação da (fluida) zona adverbial das causalidades. Conjugando-se pressupostos cognitivistas e funcionalistas para uma análise da língua em uso, analisa-se as relações adverbiais de causa, de condição e de concessão a fim de verificar quais as propriedades semânticas e pragmáticas por meio das quais se observam áreas de contraste e de sobreposição entre essas três categorias. O tratamento conferido a essas relações adverbiais prevêsque elas sejam consideradas categorias que apresentam membros prototípicos, ou seja, os mais representativos, e membros periféricos, que se distanciam da exemplaridade e podem se alocar em áreas de transição categorial. Em última instância, argumenta-se a favor de uma visão não engessada das categorias gramaticais, neste caso, a categoriais das relações adverbiais, dando-se continuidade a estudos funcionalistas e cognitivistas que seguem nessa direção como Dancygier e Sweetser (2005) e Neves $(2010,2012)$.
\end{abstract}

Palavras-chave:Relações adverbiais. Categorias gramaticais. Fluidez de limites.

Abstract: This article is an investigation of the fluid linguistic adverbial zone of causalities. By conjugating functional and cognitive premisses in order to analyze language in use, we analyze the adverbial relations of cause, condition and concession aiming at identifying the semantic and pragmatic parameters through which we observe areas of contrast and overlap between these categories. The treatment given these adverbial relations presupposes that they be considered categories which present more prototypical members, that is, exemplar members, and more peripheral members, that may be allocated in areas of transition between categories. Ultimately, we argue in favor of a view a non-rigid grammatical categories, in this case, the category of adverbial relations, giving continuity to a trend of studies in functional and cognitive linguistics such as Dancygier and Sweetser (2005) and Neves (2010, 2012).

Keywords: Adverbial relations. Grammatical categories. Fuzzygrammar.

\footnotetext{
${ }^{1}$ Este artigo faz parte do projeto de mestrado "Os juntivos causais e concessivos do português brasileiro na perspectiva cognitivofuncional: uma análise da ligação conceptual dos elementos gramaticais em uso nessa zona adverbial" financiado pela FAPESP (processo 2012/23239-6).
} 



\section{Considerações iniciais}

Compatível com a visão de uma língua que se presta à comunicação entre os falantes é a visão de categorias linguísticas não discretas, mas, sim, fluidas e altamente indeterminadas, pois estão em jogo pressões do uso e um conjunto de fatores cognitivos que moldam a estrutura da língua. Cada categoria, por sua vez, apresenta membros prototípicos, isto é, aqueles que dela são mais representativos, e aqueles membros que, distantes da região central, alocam-se nas regiões periféricas, regiões estas que, muitas vezes, podem ser áreas de transição entre categorias. Esse modo de organização confere às categorias um caráter de radialidade. As categorias linguísticas são, portanto, categorias radiais, como denomina Lakoff (1987).

Para o português, Neves (2012, cap. 05) tratou da relativização entre as fronteiras categoriais dos substantivos e adjetivos, mostrando que, em casos como 'navio fantasma', em que se tem dois substantivos formando um nome composto, 0 substantivo à direita ('fantasma') "perde" sua propriedade referencial, própria dos nomes substantivos, e passa a funcionar como um qualificador/atributivo, próprio dos nomes adjetivos. A mesma autora (NEVES, 2010; 2012, cap. 08) já tratou também da relativização de fronteiras entre as categoriais das relações adverbiais de causa, condição e concessão, abrigando-as na zona semântica das causalidades (seção 04). É justamente neste último campo de investigação, o das relações adverbiais, que este trabalho se insere.

Há que se considerar, se o que se propõe é verificar as sobreposições categoriais, que a imprecisão entre as tais fronteiras, como será mostrado na seção 03 adiante, é principalmente motivada por fatores de ordem cognitiva, que dizem respeito ao modo de organização dessas categoriais. As categorias linguísticas, assim como outras categorias conceptuais, naturalmente, apresentam áreas de contraste (isto é, propriedades específicas), mas também apresentam áreas de sobreposição, em que se observam propriedades em comum por elas compartilhadas.

Este artigo propõe-se a uma investigação da língua em uso, conjugando-se os pressupostos teóricos do Funcionalismo e do Cognitivismo, duas vertentes linguísticas preocupadas com a vivência da linguagem, para uma análise da zona semântica das causalidades e das construções adverbiais a ela pertencentes. Toma-se, como o território de análise, as construções adverbiais de causa, condição e concessão, conferindo-se a essas construções uma visão categorial.

Para tanto, este texto assim se organiza: na seção 02, trata-se da imprecisão de fronteiras categoriais e as implicações disso para a descrição gramatical e para a sistematização do uso linguístico, argumentando-se, em última instância, contra um visão "engessada" das categorias; na seção 03, apresentam-se argumentos a favor da centralidade da percepção de relações causais para a cognição e para a estrutura linguística, já direcionando-se para um exame das relações adverbiais em análise; na seção 04, faz-se uma caracterização, com base em critérios semânticos e pragmáticos, das relações adverbiais de causa, condição e concessão; na seção 05 , procede-se ao exame das áreas de sobreposição e de contraste, com base nos critérios semânticos e pragmáticos estabelecidos na seção anterior, entre as relações em exame; na seção 06, por fim, tecem-se considerações finais sistematizando as generalizações apresentadas neste trabalho.

\section{A imprecisão de limites categoriais}

Tanto a linguagem quanto a cognição humana estão conceptualmente organizadas por meio de categorias, cujos limites não são discretos e, portanto, cujos membros frequentemente se sobrepõem. Berlin e Kay (1969), entre outros, verificaram essa imprecisão na categorização de cores; Rosch (1975) verificou essa imprecisão na categorização de móveis domésticos e de tipos de pássaro; Lakoff (1987) analisou três casos dessa imprecisão de fronteiras (dois dos quais pertencentes ao domínio gramatical) e 
suas implicações para o uso da linguagem. Um semnúmero de estudos já verificou essa imprecisão entre limites categoriais, e a conclusão a que chegam é a de que a fluidez entre as categorias conceptuais é um fenômeno cognitivamente motivado, que se estende às categorias linguísticas, sendo ele observável na gramática das línguas naturais.

Nessa direção, Langacker (1987, p.370) afirma que "os fatos da língua ditam um tratamento nãoreducionista para a categorização" ${ }^{2}$. Assim o é porque a perspectiva de que a língua é tanto uma estrutura simbólica (por meio da qual as estruturas conceptuais humanas se organizam) quanto um instrumento de comunicação de experiências conceptualizadas implica o não discretismo e a gradiência das categorias de que a língua dispõe, bem como a gradiência de pertencimento dos itens linguísticos e gramaticais a essas categorias.

Como aponta Bybee (2010), esse caráter gradiente das categorias linguísticas e a presença da variação na língua não são argumentos contra o estudo e a descrição dos padrões linguísticos que emergem no uso; pelo contrário, a descrição das generalizações, a partir de semelhanças e de traços comuns encontrados nos membros das categorias, é essencial ao estudo gramatical, visto que a "categorização estabelecida faz parte conhecimento de um falante sobre convenções linguísticas"33(LANGACKER, 1987, p.370).

Essa visão de uma linguagem que compreende categorias fluidas não exclui uma sistematização da organização categorial na gramática da língua; exclui, apenas, a premissa de que o significado da linguagem reside em um "check-list" de propriedades submetidas a valor de verdade (FILLMORE, 1975). Defende Lakoff (1987) que, na visão cognitiva, a gramática como "pura forma" é incompatível com as realidades cognitiva e comunicativa, pois o significado produzido na linguagem a partir da gramática -iisto é, a propriedade semântica da gramática - emerge

\footnotetext{
${ }^{2}$ Tradução deste autor. Texto original: "The facts of language [...] dictate a nonreductive approach to categorization".

${ }^{3}$ Traduçãodesteautor. Texto original: “[...] established categorization is part of a speaker's knowledge of linguistic conventions".
}

justamente do componente experiencial e imaginativo da cognição humana, componentes esses que determinam a formação e a organização de categorias conceptuais.

\section{A causalidade na cognição e na linguagem}

A noção de causalidade é essencial à cognição humana. Prever possíveis efeitos a partir de causas conhecidas, ou, ainda, prever possíveis causas (desconhecidas) a partir de efeitos conhecidos são operações cognitivas essenciais à sobrevivência humana e à realização até mesmo de tarefas simples. Segundo a Física teórica, não existem causas no mundo externo. Fala-se, na verdade, de forças e de uma orgânica relação entre essas forças, sendo possível determinar quais delas levaram a mudanças de estado ou, ainda, "originaram" outras forças (WACHTER; HOEBER, 2006). Na dimensão cognitivo-perceptiva, pesa, sobre os indivíduos, então, a responsabilidade de categorizar "forças" e eventos para que se estabeleçam as devidas relações causais entre elas.

A percepção de eventos sucessivos pode suscitar a relação de causalidade entre eles. $\mathrm{Na}$ língua, os falantes utilizam construções nas quais a simples adjunção de dois eventos pode sugerir uma leitura causal. Neves (2012) propõe a existência de uma correspondência básica entre as construções (hipotáticas) causais, introduzidas pela conjunção porque, e as construções (paratáticas) aditivas, introduzidas por e. A ocorrência (01), retirada de Neves (2012, p.169), foi reescrita pela autora em (01').

(01) Não sabia, e isso o torturava mais do que tudo. $^{4}$

(01') Isso torturava-o mais do que tudo porque não sabia.

A construção cognitiva da cena representada em (01) é primitiva. Ambos os eventos estão

\footnotetext{
${ }^{4}$ Em todas as ocorrências, os itens juntivos aparecem destacados em negrito.
} 
ordenados como temporalmente sucessivos, primeiro não sabia e, depois, isso (o não saber o torturava mais que tudo). Essa representação cognitiva é expressa por meio de expedientes linguísticos que deixam marcada a iconicidade básica entre os eventos (a conjunção e). Não existe vínculo causal afirmado entre esses dois eventos que compõem a cena em (01). No entanto, por implicatura, em termos griceanos (GRICE, 1975), pode-se licenciar essa leitura em (01'). Inverter a ordem dos eventos, escolhendo manter a construção (paratática) aditiva, incorreria na mudança da representação dos eventos feita pelo falante ${ }^{5}$.

\section{As relações adverbiais de causa, de condição e de concessão}

$\mathrm{Na}$ seção 03, tratou-se das representações cognitivas da causalidade e algumas construções linguísticas por meio das quais o falantes comunicam a experiência da causalidade. Nesta seção, foca-se especialmente nas relações adverbiais cujo componente semântico básico é a causalidade, a saber: a relação adverbial de causa, de condição e de concessão. Conforme já anunciado nas Considerações Iniciais, reconhece-se que há também as relações adverbiais concessivo-condicional das quais, contudo, não se trata neste artigo.

Neste ponto é necessária uma distinção entre os termos "zona das causalidades"e "relação adverbial causal", pois ambos valem-se das noções de causalidade. Na primeira expressão, causalidade deve ser entendida como a representação conceptual bem como os modelos cognitivos idealizados resultantes da conceptualização dos elos de causa e efeito. Na segunda expressão, causalidade deve ser entendida como a representação linguística das relações de causa e efeito.

A imprecisão de limites categoriais põe-se como um fenômeno básico na investigação dos fatos linguísticos em uso. Visto que o que se propõe é

\footnotetext{
${ }^{5}$ R. Lakoff (1971), Sweetser (1990), entre tantos outros, jánotaram que esse princípio da iconicidade da adição inerente àconjunção e explicaria a multiplicidade de sentidos que essa conjunção pode estabelecer. Neves (2012, p.169, nota 4) também faz indicações na mesma direção.
}

justamente verificar, por meio da análise dessas construções (adverbiais) introduzidas por itens juntivos complexos, áreas nas quais a categoria de causa, de condição e de concessão se contrastam e se sobrepõem. Por exemplo, uma construção concessiva como (01) pode muito bem licenciar a contraparte causal de (02) e a condicional de (03), ainda que, para isso, entrem em jogo outras categorias linguísticas, como a polarização (que é dispensada nos dois últimos exemplos) e a correspondência modo-temporal entre os verbos de cada segmento.

01) Embora o tribunal seja eventualmente desrespeitado por alguns ministros, é preciso que os demais defendam a dignidade do país.

(CDP:19Or:Intrv:ISP)

(02) Éopreciso que os demais defendam a dignidade do país porque o tribunal eventualmente será desrespeitado por alguns ministros.

(03) Se o tribunal, eventualmente for desrespeitado por alguns ministros, será preciso que os demais defendam a dignidade do país.

Outras construções concessivas (04) podem manter com a causalidade (05) um vínculo mais forte do que com a condicionalidade (06). Nesses casos, a leitura causal é perfeitamente licenciada, a leitura condicional, contudo, é inconsistente. Um dos motivos pelos quais essa leitura é inconsistente é na falta de correspondência entre os tempos e modos dos verbos do segmento condicional e do segmento nuclear.

(04) Tínhamos muitas portas de acesso aos acontecimentos, ainda que [...] não pudéssemos passar esse conhecimento à frente.

(CDP:190r:Intrv:ISP)

(05) Porque tínhamos muitas portas de acesso aos acontecimentos, podíamos passar esse conhecimento à frente.

(06) ?? Se tínhamos muitas portas de acesso aos acontecimentos, podíamos passar esse conhecimento à frente. 
Ocorre que, como lembra Dancygier (1998), tomados na perspectiva cognitivo-funcional, todos os aspectos estruturais (e, portanto, composicionais) das construções gramaticais 'co-laboram' no estabelecimento do sentido global da construção, por meio de expedientes já, convencionalizados da estrutura linguística. Segundo a autora, a tarefa, nessa perspectiva, é descobrir como se mapeiam sentidos às formas gramaticais, isto é, como forma e sentido interagem na obtenção de efeitos pragmáticos. Um dos possíveis caminhos a se percorrer na análise da maneira como os sentidos se mapeiam às formas gramaticais de modo a obter efeitos pragmáticos pode centrar-se na investigação dos seguintes parâmetros (não sendo necessário ficar restrito a estes): o tipo de item juntivo que introduz o segmento adverbial; a correspondência de tempo e modo verbais; a ordem dos segmentos; e o grau de (inter)subjetividade das construções.

Com base nesses conceitos e princípios de funcionamento da linguagem, o que se faz, no restante deste artigo, é inserir as categorias de causalidade, de condicionalidade e de concessividade numa zona categorial mais ampla, a zona de causalidades, a qual abarca também a categoria condicional-concessiva, não considerada nesta análise, por meio de um exame da inter-relação das construções linguísticas pertencentes a essa grande zona categorial (NEVES, 2012).

\section{Um exame da zona adverbial das causalidades: as áreas de sobreposição e contraste}

Nas duas seções precedentes a esta, ficou assentado que as relações de causa e de concessão são, primariamente, relações de natureza conceptual, cuja manifestação linguística geralmente se dá por meio de um complexo oracional, formado de um segmento nuclear e um segmento causal ou concessivo. Nesse complexo, pode, ou não, haver a presença de um item juntivo ${ }^{6}$ que explicite a relação

\footnotetext{
${ }^{6}$ A principal alegação dos estudos discursivos -como o de Taboada (2009) e o conjunto de estudos em Sanders et al
}

de causa ou de concessão estabelecida entre os segmentos ${ }^{7}$. Essas relações formam, juntamente com a de condição ${ }^{8}$, um continuum categorial, altamente fluido, referido na literatura, principalmente por Neves (2010, 2012), pelo termo "zona de causalidades".

Para Kortmann e Couper-Kuhlen (2000), essas três relações podem ser conceptualizadas umas em relação às outras, a condicionalidade sendo a hipotetização de uma causa, e a concessividade, a sua negação. Respaldados por estudos como o de Harris (1988) e os de König (1986, 1988), esses autores afirmam que causa e concessão são relações altamente imbricadas uma na outra, sendo a concessividade a expressão da inoperância da causalidade.

Compartilham dessa perspectiva König e Siemund (2000) e Verhagen (2000, 2005), que trazem uma definição para concessividade se ancora, principalmente, na interação do pensamento causal com a operação da negação.

É possível, contudo, entender essas relações tomando-se outra perspectiva. Estudos como os de Neves (2000, 2010, 2012), assumem a condicionalidade como o ponto de articulação entre a causalidade e a concessividade, sendo a causa conceptualizada em termos de condições preenchidas, e a concessividade em termos de condições insuficientes, preenchidas ou não.

Em uma construção concessiva introduzida pela conjunção embora, como a que segue, observase um modelo básico de causalidade.

(07) Embora a maior parte da programação ainda seja gravada no sistema tradicional, a emissora dispõe de câmeras digitais $e$ ilhas de edição e já realizou vinhetas e alguns programas com a nova tecnologia.

(CDP:19N:Br:SP)

(orgs. 2001) -segundo a qual não énecessário haver um item juntivo explicitando a relação entre segmentos, visto que o conteúdo proposicional de cada segmento jáéo suficiente para que o ouvinte construa uma representação cognitiva dessa relação.

${ }^{7}$ Neste artigo, contudo, estão em foco apenas as construções marcadas por meio de um item juntivo.

${ }^{8}$ Háestudos que, àzona de causalidades, acrescenta as categorias de finalidade e de consecução, como éo caso de Gálan Rodriguez (1999). Aqui, contudo, essas duas categorias não serão levadas em consideração. 
Nessa construção, gravar no sistema tradicional pressupõe ${ }^{9}$ que a emissora não disponha da tecnologia necessária para gravar no sistema atual. Nesse sentido, a pressuposição do segmento concessivo licenciaria a correspondência com a relação de causa em $A$ emissora grava no sistema tradicional porque não dispõe de câmeras digitais.

Portanto, nas construções concessivas, está em jogo um conjunto de pressuposições, mais bem rotuladas como "modelos cognitivos idealizados" (LAKOFF, 1987), que licenciam a relação entre concessividade e a causalidade. Nas construções concessivas, o contraste estabelecido entre o segmento nuclear e o segmento concessivo nasce justamente da pesagem verificativa que o falante dos modelos idealizados, conforme será mostrado mais adiante. A correspondência com uma expressão de condicionalidade $^{10}$, por outro lado, como em Se eles tivessem câmeras digitais, eles gravariam em tecnologia atual e uma correspondência subsidiária, derivada dos modelos cognitivos idealizados de causa.

König e Siemund (2000) sistematizam o continuum categorial causa-condição-concessão valendo-se das noções de duas dicotomias: harmonia versus dissonância e hipotético versus factual. É o que sistematiza o Quadro 01 abaixo.

Quadro 01. Relações de significado causal, condicional, concessivo-condicional e concessivo

\begin{tabular}{|c|c|c|}
\cline { 2 - 3 } \multicolumn{1}{c|}{} & Hipotético & Factual \\
\hline Harmonia & Condicional & Causal \\
\hline Dissonância & $\begin{array}{c}\text { Concessivo- } \\
\text { condicional }\end{array}$ & Concessivo \\
\hline
\end{tabular}

Fonte: Adaptado de König e Siemund (2000, p. 342)

\footnotetext{
${ }^{9}$ Entenda-se 'pressuposição' de acordo com as noções pragmáticas (LEVINSON, 1983), segundo as quais a pressuposição éum tipo de inferência pragmática.

${ }^{10}$ São traços básicos do pensamento condicional a predição e a alternância, como propõem Dancygier (1998) e Dancygier \& Sweetser (1996). Explicam essas autoras que tais traços sósão possíveis porque os indivíduos constroem "modelos [cognitivos] idealizados"do mundo, podendo, então, fazer previsões e levantar hipóteses sobre outras realidades a partir daquilo que étomado como conhecido.
}

Verticalmente, no quadro, estão as categorias da harmonia e da dissonância, que dizem respeito à possível co-ocorrência e à possível concomitância das situações descritas nos segmentos nuclear e adverbial, sendo harmônicas as situações concomitantes, e dissonantes as situações opostas. Horizontalmente, estão as categorias do hipotético e do factual. Tanto as construções causais quanto as construções concessivas asseveram a veracidade da factualidade dos segmentos em combinação, enquanto as condicionais e as concessivocondicionais hipoteticizam a veracidade dos segmentos em combinação.

Nesse direcionamento, a causalidade e a concessividade são sempre factuais, ao passo que a condicionalidade é totalmente hipotética. A condicionalidade é explicável pelos traços de harmonia e de hipoteticidade entre as situações. Colocam-se nesse quadro de relações, as construções concessivo-condicionais, cujo significado é explicável pela hipoteticidade e pela dissonância entre as situações descritas nos segmentos. Tanto as construções concessivas quanto as concessivocondicionais, nas quais se observa uma aparente oposição entre as situações descritas nos segmentos, pertencem à categoria da dissonância.

Observando-se o Quadro 01, verifica-se que o fator relevante na distinção entre a causalidade e a concessividade é a dissonância, ou a "oposição" aparente entre os segmentos.

Neves (2000, p.867), nesse mesmo espírito dos autores, propõe a seguinte representação para a zona da causalidade.

Figura 01. A zona da causalidade

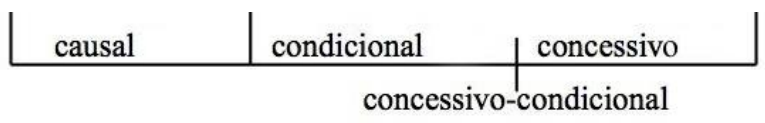

Fonte: Adaptado de Neves (2000).

A zona concessivo-condicional, em português, geralmente assume construções com 0 item juntivomesmo se, mas também podem ser consideradas as construções como indica Bechara 
(2009, p.498) de onde se retiraram os exemplos seguintes:

(08) Quer estudes, quer não, aprenderás facilmente a lição.

(09) Ou estudemos medicina, ou sejamos advogados, conquistaremos na sociedade um lugar de relevo.

Na visão de König (1988, p.146), cuja análise se apoia em noções pragmáticas, as construções causais podem ser analisadas em termos de uma condição contrafactual, sendo possível determinar a relação causal entre o segmento nuclear e o segmento causal. Em uma construção causal como no exemplo oferecido por König $(1988$, p.)

\section{(10) I did not go out because it was raining ${ }^{11}$}

a relação entre o segmento nuclear q [/ didnot go out] e o segmento causal p [because it wasraining] pode ser analisada por vias de uma relação condicional contrafactual do tipo Se não estivesse chovendo, eu teria saído, por meio da qual fica estabelecido o vínculo causal hipotetizado. Para a análise das construções concessivas, propõe 0 autor que 0 vínculo causal seja evidenciado por meio de uma pressuposição (ou implicatura convencional), inerente ao próprio pensamento concessivo. Dessa forma, em uma construção concessiva como

\section{(11) Although John had no money, he went to this expensive restaurant ${ }^{12}$}

o segmento concessivo p [Although John had no money] apresenta a implicação $x$ [quem não tem dinheiro, normalmente, não vai a restaurantes caros]; tal implicação $x$, contudo, é negada pela asserção feita no segmento nuclear q [hewenttothisexpensiverestaurant]. Conclui 0 autor que, nas construções concessivas, a relação entre os segmentos se dáepor meio de uma pressuposição, e,

\footnotetext{
11 Tradução: (10) Eu não saíporque estava chovendo.

12 Tradução: (11) Embora John não tivesse dinheiro, ele foi a um restaurante caro.
}

nas construções causais, por meio de um acarretamento.

\section{Considerações finais}

As construções adverbiais mostram-se um território frutífero para a investigação da interação entre sintaxe, semântica e pragmática (investigação própria do funcionalismo) na linguagem em uso, pois para elas a língua dispõe de um sem número de expedientes que cooperam na construção simbólica do significado.

Por um viés semântico, chega-se a seguinte caracterização para as relações de causa, condição e concessão:

a) as relações causais e as concessivas são, prototipicamente, factuais, pois implicam a verdade dos segmentos $p$ e $q$.

b) a relação condicional é, prototipicamente, eventual, ou hipotética, pois está implicada uma alternatividade entre $p$ e $q$.

Pode-se chegar a essa mesma caracterização observando-se as operações de polarização, conforme indicado nas seções 04 e 05.

a) a relação causal está no polo do "sim", pois, nela, a causalidade é afirmada.

b) a relação concessiva está no polo do "não", pois, nela, a causalidade é negada;

c) a relação condicional está na zona de transição entre o "sim" e o "não", portanto, está na zona do "talvez", pois, nela, a causalidade é questionada.

Considerações nessa direção já foram feitas por Neves (2012). O veio que a autora assume em sua análise permite a postulação de que essas propriedades apresentadas são, na verdade, as propriedades prototípicas de cada uma das relações adverbiais. A autora ainda conjuga essas relações adverbiais com as propriedades de factualidade, eventualidade e contrafactualidade. Dessa conjugação, obtêm-se as dicotomias: causalidade xfactualidade, condicionalidade $x$ eventualidade, concessividadexcontrafactualidade. Essas dicotomias, na visão da autora, montam o cenário das 
relações adverbiais de causa, de condição e de concessão. Por caminhos diferentes, chega-se, neste artigo, a este mesmo cenário.

Finalmente, procurou-se deixar assentado que apesar de o exame das relações adverbiais de causa, condição e concessão poder ser feito por diferentes prismas, seja tomando-se a causalidade seja tomando-se a condicionalidade como ponto de partida, deve-se assumir a centralidade do arrazoamento causal, bem como dos modelos cognitivos idealizados que fazem parte desse arrazoamento na caracterização de cada uma das relações adverbiais em exame. Esse fato se mostra especialmente verdade para o exame das relações adverbiais concessivas, que se encontram no ponto extremo da zona semântica das causalidades.

\section{Referências}

BECHARA, E. Moderna Gramática Portuguesa. 37ª edição. Rio de Janeiro: Editora Nova Fronteira, 2009.

BYBEE, J. Language, usage and cognition. Cambridge: CUP. 2010.

COUPER-KUHLEN, E.; KORTMANN, B. Introduction. In: COUPER-KUHLEN, E.; KORTMANN, B. (Org.). Cause, condition, concession, contrast: cognitive and discourse perspectives. Berlin: Mouton de Gruyter. 2000.

DANCYGIER, B. Conditionals and prediction. Cambridge: CUP. 1998.

DANCYGIER, B.; SWEETSER, E. Conditionals, distancing, and alternative spaces. In: GOLDBERG, Adele. Conceptual structure, discourse and language. Stanford: CSLI. 1996.

FILLMORE, C. An alternative to checklist theories of meaning. In: Proceedings of the First Annual Meeting of the Berkeley Linguistics Society.1975.

GALÁN-RODRIGUEZ, C. La subordinación causal y final. In: BOSQUE, I.; DEMONTE, V. (org.). Gramática descriptiva de lalenguaespañola. vol. 3. Madrid: ColecciónNerija y Bello. 1999.

GRICE, H. P. Logic and conversation. COLE, P.; MORGAN, J. L. Syntax and semantics: speech acts. New York: Academic Press. 1975.

HARRIS, M. Concessive clauses in English and Romance. In: HAIMAN, J.; THOMPSON, S. Clause combining in grammar and discourse. Amsterdam: John Benjamins. 1988.
KÖNIG, E. Conditionals. concessive conditionals and concessives: areas of contrast, overlap and neutralization. In: TRAUGOTT, $E$. et al. On conditionals.Cambridge: CUP. 1986.

KÖNIG, E. Concessive connectives and concessive sentences: cross-linguistic regularitites and pragmatic principles. In: HAWKINS, J. (Org.). Explaining language universals. New York: Basil Blackwell. 1988.

KÖNIG, E.; SIEMUND, P. Causal and concessive clauses: formal and semantic relations. In: COUPERKUHLEN, E.; KORTMANN, B. (Org.) Cause, condition, concession, contrast: cognitive and discourse perspectives. Berlin: Mouton de Gruyter. 2000.

LAKOFF, G. Women, fire and dangerous thingsomwhat categories reveal about the mind. Chicago: Chicago University Press. 1987.

LAKOFF, R. If's, and's and but's about conjunctions. In: FILLMORE, C.; LANGÈNDOEN, T. Studies in linguistic semantics. New York: Holt, Reinhart \& Winston. 1971.

LANGACKER, R. Foundations of Cognitive Grammar: theoretical prerequisites. vol 1. Stanford: Stanford University Press. 1987.

LEVINSON, S. Pragmatics. Cambridge: CUP. 1983.

NEVES, M.H.M. Gramática de Usos do Português. São Paulo: Editora Unesp. 2000.

NEVES, M.H.M. Ensino de língua e vivência de linguagem. São Paulo: Editora Contexto. 2010.

NEVES, M.H.M. A gramática passada a limpo. São Paulo: Parábola. 2012.

SANDERS, T.; et al (org). Text representation linguistic and psycholinguistic aspects. Amsterdam: John Benjamins. 2001.

SWEETSER, E. From etymology to pragmatics. Cambridge: CUP. 1990.

VERHAGEN, A. Concession implies causality, though in some other space. In: COUPER-KUHLEN, E.; KORTMANN, B. (Org.) Cause, condition, concession, contrast: cognitive and discourse perspectives. Berlin: Mouton de Gruyter. 2000.

VERHAGEN, A. Constructions of intersubjectivity: discourse, syntax and cognition. New York: Oxford University Press. 2005.

TABOADA, M. Implicit and explicit coherence relations. In: RENKEMA, J. Discouse, of course. Amsterdam: John Benjamins. 2009.

WACHTER, A.; HOEBER, H. Compendium of theoretical physics. New York: Springer. 2006. 